\title{
The question of "representation" in the psychoanalytical and cognitive-behavioral approaches. Some theoretical aspects and therapy considerations
}

\author{
Philippe DeTimary ${ }^{1 *}$, Susann Heenen-Wolff ${ }^{2 \dagger}$ and Pierre Philippot ${ }^{2 \dagger}$ \\ Academic Hospital Saint-Luc and Department of Adult Psychiatry, Institute of Neuroscience, University of Louvain, Brussels, Belgium \\ 2 Institute of Psychology, University of Louvain, Louvain-la-Neuve, Belgium
}

\section{Edited by:}

Martial Mermillod, Clermont University,

France

\section{Reviewed by:}

Martial Mermillod, Clermont University,

France

Alexandre Schaefer, University of

Leeds, UK

Nadia Chakroun, University of

Clermont, France

${ }^{*}$ Correspondence:

Philippe De Timary, Department of Adult Psychiatry, Institute of

Neuroscience, Catholic University of

Louvain, Avenue Hippocrate 10, B 1200

Brussels, Belgium.

e-mail: philippe.detimary@uclouvain.be

'Philippe De Timary, Susann Heenen-Wolff and Pierre Philippot have identically contributed to this article.
This paper compares the cognitive-behavioral and psychoanalytical approaches with respect to the way in which each of them conceives of representation and deals with the issues that this involves. In both of them conscious and latent (unconscious) representations play a crucial role. Highlighting similarities and differences facilitate communication on a theoretical level but also prove helpful to the clinical practitioners involved. We try to put forward an attempt at comparison, with the idea of going beyond the - obviously important - differences in vocabulary. In this attempt at comparison, we have successively compared the definitions of representation and the respective therapeutic interventions proposed by each approach. There are no doubt many overlapping elements in the way in which the workings of the mind are conceived of in these approaches, particularly as regards their links with affects. We next developed the implications of representation deficits in pathology, suggesting the important role played by elements that are avoided, suppressed from memory or repressed, and with respect to the need to treat such material in a specific manner so as to ensure some progress as to the symptoms presented. We finally summarized common and distinct aspects of the two perspectives. The very fact that two approaches that follow very distinct methodologies reach the same conclusion concerning the importance of distortions and failures of representation in generating mental distress strengthens, in our view, the epistemological reliability of the role of representation in psychopathology.

Keywords: psychopathology, psychotherapy, comparison, theory, practice, methodology

\section{INTRODUCTION}

The aim of this theoretical paper is to compare the cognitivebehavioral and psychoanalytical approaches with respect to the way in which each of them conceives of representation and deal with the issues that this involves. Although their theoretical background is very different, both approaches concern the same psychopathological domain. In addition, as we shall see, in both of them conscious and latent (unconscious) representations play a crucial role. It is for this reason that, in our view, it is interesting to explore how, both theoretically and clinically, these two methods conceive of and deal with representation. Highlighting these similarities and differences may not only facilitate communication on a theoretical level but also prove helpful to the clinical practitioners involved: We would argue that the more detailed are the theoretical concepts that clinicians have at their disposal, the greater will be their ability to pay close attention to what is specific to psychopathology - i.e., the distress of those with whom they are dealing - to understand it, and to treat it successfully. Also, the decision as to which specific form of psychotherapy to undertake would then be based on a more fundamental understanding of the different techniques. As we all know, scientific discussion between clinicians who carry out cognitive-behavioral therapies (CBT) and those who practise psychoanalytical psychotherapy is very limited. This attempt at comparing the way in which these techniques approach the fundamental concept of representation is the first part of a more longterm project $^{1}$.

Generally speaking, "representation" is defined in philosophy as what one represents to oneself, the concrete content of an act of thinking ${ }^{2}$. More specifically, it is the production of a previous perception. In this paper, "representation" will be taken to mean the psychical construction - conscious and unconscious - that enables an individual to have a representation of the self and to make his or her experience meaningful. That construction depends on traces of previous experiences and on the presenting elements of the situation which at that moment is being experienced.

We have no intention of attempting to evoke similarities that go beyond what is actually the case, in a kind of syncretic approach the aim of which would be to argue that everything is just the same. On the contrary, we shall try to put forward a real attempt at comparison, with the idea of going beyond the - obviously important-differences in vocabulary; these are due to the fact that

${ }^{1}$ The second part of this project will focus on comparing the concepts of "emotional regulation" (CBT) and "internal excitation" (psychoanalysis).

${ }^{2} \mathrm{Cf}$. the Oxford English Dictionary: "the action of presenting to the mind or imagination; an image thus presented." 
the conditions under which theories are constructed in these two approaches are themselves significantly different. In constructing its theoretical corpus, the psychoanalytical approach focuses almost exclusively on the observation and understanding of clinical situations. For this reason, many of the assumptions of psychoanalysis have not been tested empirically, whereas a significant part of the concepts developed in the cognitive-behavioral approach comes from experiments on human beings or on animals. The resultant major differences in vocabulary are unavoidable.

In this attempt at comparison, we have had to isolate some aspects of these respective theorizations. We realize that, in so doing, the overall scientific constructions to which these belong will not be dealt with in their globality.

There are no doubt many overlapping elements in the way in which the workings of the mind are conceived of in these approaches, particularly as regards the pathological role played by elements that are avoided, suppressed from memory or repressed, and with respect to the need to treat such material in a specific manner so as to ensure some progress as to the symptoms presented.

There are also significant differences, particularly as regards two dimensions. The first concerns the clinical approach to traumatic representations with a view to diminishing their pathological impact. The second relates to the fact that psychoanalysis seems to focus more than does the cognitive approach on the actual content of representations.

We shall now examine the specific way in which each of these psychological techniques takes representation into account. In order to do so, we shall explain how "representation" is defined in psychoanalysis and in CBT, then show how representations are dealt with in each of these clinical approaches.

\section{HOW DO THESE PROCEDURES DEFINE "REPRESENTATION?" "REPRESENTATION" IN PSYCHOANALYSIS}

At the very beginning of his work, in his "Project for a Scientific Psychology," Freud (1950 [1887-1902]) defined representation as a construction of thinking that may be completely independent of perception. Perception implies the presence of an external object or stimulus, whereas representation may involve simply an image in memory. Some representations are conscious; the individual has easy access to them, and they are usually based on perceptions of reality. These representations can be expressed verbally, thus indicating a translation/transposition of images and ideas into words (thing-presentations becoming word-presentations) and we see here the importance of the representation format in psychoanalysis process. Given that our representations may not correspond exactly to reality, our actual experiences can help us "correct" these (for example: "I thought that I was no good at mathematics, but when I began to get good marks in that subject, with a different teacher, that "corrected" my previous - mistaken - representation of what I was capable of.").

"Mistaken" representations ("psychical reality") can have psychopathological repercussions: the spider which, for the phobic person, is much more than a simple arachnid, the lift/elevator that becomes equated with a stifling cage, the inflexible image of the "professor" which always gives the student sitting an examination a representation of being a failure. Making some impact on such representations is a crucial element in almost all current psychotherapies, because, as we know, in spite of all the explanations and experiences that might have "corrected" them, they may well still be operative. "Internal reality" - i.e., representations, patterns, pre-conceived ideas - seems in some cases to be more "real" than external reality. Internal reality then prevails over reality as such, and in return influences our perception of that reality.

We thus have within ourselves both representations that are accessible and those of which we are not conscious, which are implicit, but which nonetheless may cause considerable distress (for example: "I am very anxious whenever I have to sit an exam, but I don't know why, given that I'm a very good student." The representation of a teacher who cannot but be "wicked" is unconscious). In such a case, it is important that the therapeutic approach adopted reveals the existence of this kind of unconscious or implicit representation. For the psychoanalytical approach, it then becomes necessary to see how an unconscious representation can be made conscious. In order to understand that process it is necessary to explore both the relationship between representation and affect and the deferred retroactive effect (après-coup/ "afterwardsness").

What, then, is the relationship between representation and affect/emotion? Freud made a distinction between representation and affect. Affect is defined as belonging to the dimension of something that is "felt," not as something that can be represented; it links up with a representation but cannot as such be processed. Affect has links with representations and can move from one to another. It is this displacement of affect that makes its origins so difficult for the person concerned to interpret. The reason behind these displacements is the existence of psychical conflicts and the individual's inability to represent the situation to him- or herself, given that the affects relating to it require too much of an effort for the mental apparatus. The original representation is thus repressed/ suppressed/split-off because it is too painful and intolerable for the ego.

The relative immaturity of the infant's mental apparatus explains why, in the psychoanalytical approach, repression takes place mainly in childhood. Repression, however, applies to representation; it does not make the corresponding affect disappear once and for all. Suppression of that associated affect is therefore not completely effective. It can easily be reactivated, either spontaneously or via the encounter with an event that leads to the "return of the repressed"-i.e., a situation that revives the initial memory image or reveals to the individual a meaning of that original representation of which he or she was until then unaware (the deferred retroactive effect $)^{3}$. The work of analysis consists not only in connecting the relevant affect to its original representations, but also in making it possible to put words on the link between affects and representations: a man who consults a psychoanalyst because he feels very shy in the presence of women discovers that the shame he feels with respect to his own body and the negative representations of

${ }^{3}$ As a result of Nachträglichkeit (deferred action/après-coup), as defined by Freud (1950 [1887-1902], 1918 [1914]), a given event may not be experienced as traumatic when it actually occurs; it may become so as result of another event that brings new meaning to it. According to Laplanche (2002, p. 121), the concept of aprèscoup ["afterwardsness"] sets up a complex and reciprocal relationship between a significant event and its later re-signifying, attributing to it a new kind of psychical effectiveness. There are, then, two phases in the constitution of mental trauma: the event itself, and the moment when it becomes meaningful for the mind. 
masculinity that he has inside himself are related to the denigrating way in which, in his view, his mother saw him. Linking a current affect to representations that belong to an earlier context in his family enables such a patient gradually to distance himself from "his mother's grasp;" but distancing himself may generate anxiety because it implies also distancing himself from the representation of his mother that he has inside himself (his "internal object").

However, as Freud (1937) pointed out at the end of his life, we cannot be sure to find the "true" original affect, reason why the change of representation format gets most important (Roussillon, 1999, 2008; Golse and Roussillon, 2010). With the help of "constructions" of what is not memorable, new meanings of connections between affects and representation can be created, leading on the same time to greater flexibility.

Interestingly enough, Freud singled out two kinds of representation depending on whether they are conscious or not: "thing"presentations and "word"-presentations. Thing-presentations are simply images that cannot be put into words; they are infra-verbal. Word-presentations, on the other hand, can be expressed verbally. The phobic is "scared stiff" of spiders, but that fear cannot easily be expressed verbally; it would seem that the representative image (the spider) takes precedence over the capacity to put that fear into words. The "thing" in this case is the spider, the terrifying nature of which cannot be verbally explained in an intelligent way by the person who has that fear. If a thing-presentation is active unconsciously, mainly as an image, it has to be put into words in order for it to be accessible to treatment - it has to be expressed and thereby, at least to some extent, transformed into a word-presentation.

From the psychoanalytical point of view, two specific modes of thought are typical of these kinds of representation: "primary" (thought) processes, set up via an often "mistaken" association between images, and "secondary" (thought) processes, characterized by reasoned associations that can be expressed in words and shared through relationships with other people.

\section{REPRESENTATION IN COGNITIVE-BEHAVIORAL THERAPIES OF EMOTIONS}

Initially, behavior therapies were based exclusively on behaviorist learning theory, which rejected any implication of the idea of representation, arguing that, as a concept, it could not be observed and therefore could not be dealt with scientifically. However, in practice, one of the earliest kinds of behavior therapy developed by Wolpe (1961), systematic desensitization, was based on mental images. The person involved would gradually be exposed - in imagination - to the object of his or her fear. For instance, a snake phobic would be guided to mentally imagine encounters with snakes, with increasing levels of fear inducing features in the imagery script (for instance, moving from a placid snake to a very active one). Obviously, that approach was based on the activation of representations that had an intense emotional impact. Behavior therapy thus integrated fairly quickly what cognitive psychology was contributing, especially with respect to memory and representations. Lang (1979) was the first to set out a theory of representation that took into account what was being done in behavior therapy. From that point of view, the avowed aim of CBT became the modification of deep-lying emotional representations that led to emotional and behavioral reactions, which caused distress and suffering. Those representations were at that point thought of as being the memory trace of emotional conditioning: links between perceptual elements (stimuli) and emotional responses. Applied to the above example, snake phobia would be characterized by a rigid fear representation, i.e., an associative network comprising stimulus elements (e.g., the shape of the snake, their typical undulatory movements), response elements (e.g., accelerated heart rate, screaming, running away), and meaning elements (e.g., "danger!”).

Theorizations as regards representation in CBT have changed somewhat since then (e.g., Dalgleish, 2004). Current theories share a set of premises that we shall discuss briefly. These theories are called "multi-level" because they start from the premise according to which emotional information is represented at various cognitive levels. A distinction is made between at least two kinds of representation involved in the production and regulation of emotions: one is implicit and automatic, while the other is explicit and controlled. Philippot et al. (2007) have proposed a synthesis of multi-level approaches through their dual-memory model which differentiates between a schematic/associative system and a propositional/ conceptual one; this distinction is common to all multi-level models. The schematic/associative system corresponds to the implicit memory of emotional meanings that the individual attaches to a given situation. The propositional/conceptual system has to do with the declarative and conceptual knowledge that the person has of emotions.

The schematic/associative system (Barnard and Teasdale, 1991; Smith and Kirby, 2000) is made up of schemata. Schemata are abstract implicit representations which integrate sensory, perceptual, and semantic information from a certain category of emotional experiences with the bodily responses that are usually associated with these. For most people working in this domain, schemata are associative representations, i.e., sets of the individual's classic emotional conditionings. In other words, a schema is a general representation made up of associations between (a) perceptual indicators of the emotional situations that the individual experiences, (b) his or her bodily responses to these, and (c) the concepts and mental images that, as a rule, are activated simultaneously with the other components of the schema. For example, the perceptual features of the mother's breast, such as those resulting from touch or smell, automatically generate an approach response in the newborn. Through repetition, associations between these innate traits that generate the approach response and other sensations, such as hearing the mother's voice or smelling her perfume, are integrated into the schema.

Schemata, then, are constructed automatically by abstracting features common to various similar emotional experiences; they are constituted via the associations most frequently made in any given emotional situation. Direct experience is the only way in which information can feed into a schema. Insofar as it is a representation, a schema is not accessible to consciousness. Nevertheless, it can be inferred from the changes that it brings about, particularly as regards sensations and bodily modifications. For example, someone who suffers from panic attacks could infer his or her panic schema by observing, via those panic experiences, what permanent features exist between his or her perceptions, thoughts, and mental images on the one hand and bodily panic reactions on the other. 
The propositional/conceptual system is a kind of explanatory theory concerning emotions. It is made up of distinct concepts which represent the various elements of any given emotional situation. Its knowledge base is a set of specific meanings: discrete concepts or mental images are joined together by specific semantic or episodic relationships - for example, the idea that muscular tension is an attribute of anger. The propositional knowledge base can be activated intentionally and consciously, either verbally or in pictorial mode. It enables emotions to be identified and communicated verbally, and facilitates problem-solving in emotional situations. Any information that can be carried over into a network of propositional concepts can be incorporated into the propositional system. In this way, the units of the system can be built up on the basis of conversations, readings, and experiences.

These two kinds of representation, schematic and propositional, are in some ways linked together. As we have pointed out, concepts or mental images (propositional level) can be integrated within schemata (schematic/associative level). Take, for example, the case of someone who suffers from panic disorder as an illustration of what we are saying. In such a person, a series of perceptual indicators (bodily sensations) activates a schematic representation of panic which includes representations and activation of bodily responses (hyperventilating, tachycardia, etc). When such a person is panicking, he or she tries to understand what is going on - and the most frequent interpretation is that of having a heart attack. Thus, when the individual's panic schema is activated, he or she activates also concepts and mental images that have to do with cardiac arrest. If this is repeated, the concepts and mental images prototypically activated when the person feels panicky become associated with the panic schema. The activation of panic thus makes more accessible the ideas and images associated with a heart attack, and vice versa: every image or concept linked to that theme automatically activates the schema and its response - panic. A Valentine card, for example, representing a big heart may automatically trigger a panic attack in someone who suffers from that disorder.

\section{A COMPARISON BETWEEN THESE TWO CONCEPTUALIZATIONS OF REPRESENTATION}

The psychoanalytical conception and that prevalent in the cognitive-behavioral domain do therefore converge to some extent. Representations may be either conscious or unconscious; some can be activated automatically while others are activated voluntarily. They depend on past experiences. Nevertheless, there are some major differences, the main one no doubt being the fact that, in psychoanalysis, an affect does not necessarily originate in the representation or the circumstances that the person concerned evokes. It can move from one representation to another, which is why the emotion, affect, and symptom presented by that person will be explored as to their true origins in the course of the treatment process.

The point of view adopted by cognitive theories is quite different: A given emotion is an integral part of the representation and the associative links are both many in number and difficult to modify. The affect/emotion is inextricably linked to its context, i.e., the antecedents that activate it and the responses and consequences that it entails. Generalizations of that emotional response may, of course, be observed; the affect is thus evoked also by other elements associated with the initial context. Even in this case, however, the affect remains linked to the initial representation that brought it about. For instance, for someone having once experienced excruciating panic in a gun fight, later exposure to loud noises, in totally different contexts (e.g., a firework), will trigger the panic again.

Another difference lies in the way in which these theories conceive of the relationship between image, verbalization, and conscious and unconscious processes. In psychoanalysis, "transiting via an image" plays a major role in becoming conscious of one's unconscious representations. The work of analysis makes it easier for these to be expressed as images of one kind or another, through the importance it attaches to dreams and to free association. Becoming conscious of something follows on from a process whereby words are put on such images: A thing-presentation is transformed into a word-presentation, and this process also enables the affect to be bound. Images therefore play a very important role in the process that enables an element to become conscious. For cognitive theories, image-based non-verbal representations can be conscious - moreover, since image-based representations often have a strong emotional intensity (Holmes and Mathews, 2005), they tend to be immediately noticed by the person concerned; some writers argue that words weaken this as they become conscious and cut off part of the representation (cf. the theory of mindfulness, Philippot, 2007a, and that of embodied cognition, Barsalou, 1999).

A third difference lies in the fact that psychoanalysis, to a greater extent than cognitive approaches, focuses on the content of representations and especially on the fact that some of these are shared by a significant number of people; there is, therefore, a kind of "community of content" which entails a specific kind of theoretical work in psychoanalysis and directs the analyst's attention to certain aspects of what the patient is saying. These contents are universal in nature and they structure, in each and every one of us, the workings of our mind and our fundamental representations. The great myths shared by all humankind could be seen as a product of this. The best-known example is the Oedipus complex: the bodily experiences and representations linked to this ("infantile sexuality") set up, in the child, the processing of the difference between the sexes and between generations. In the cognitive-behavioral approach, there have been over time some developments in the manner in which the question of content has been treated. Initially, the focus was both on the thought processes involved - in particular the cognitive distortions that result in a biased perception of reality - and on certain kinds of content or thematics - in particular "individual irrational beliefs" (Ellis, 1977) or "schemata" (Beck et al., 1979). These concepts refer to representations that remain inaccessible to consciousness, relating to the self, to others and to the world in general. For instance, a belief or schema could be that "one must act perfectly in order to be accepted, else he/she will be rejected". Such schema would lead the person to focus on indices of imperfection in his/her action, neglecting other aspects, and consequently generating a distorted view of him/herself. Unlike the psychoanalytical approach, contents of representations are not here thought of as being universal in nature ("Oedipus complex"); they apply only to the individual(s) concerned. As a result, these representations have not been theorized on any general level with respect to their content. However, from a functional point of view, these representations, via the "cognitive distortions" that they entail, 
would appear to determine how reality is interpreted and, therefore, our behavioral and emotional reactions to it. Subsequently - and this is the current position - CBT came to focus on thought processes as such (Harvey et al., 2004). The difficulties that a person finds him- or herself facing - and, more specifically, the fact that they persist without any natural solution being found to resolve them - are not so much due to the content of what the individual is worried about as a result of the way in which he or she treats the information relating to this concern. For example, in this way of looking at the situation, depression is triggered and subsequently maintained not so much by the content of the depressed person's thoughts ("I am worthless and everything is hopeless") as by the manner of his or her thinking: abstract and verbal rather than concrete and image-based, focusing on the analysis of the causes and consequences of his or her situation rather than on how it is experienced (Watkins, 2008).

\section{THE THERAPEUTIC APPROACH}

From the psychoanalytical point of view, thought processes that apply to thing-presentations ["primary (thought) processes"] emerge for example in dream-images and also - at least to some extent - through free association (Bollas, 2006). Wordpresentations ["secondary (thought) processes"] enable situations to be expressed in words and belong to the field of consciousness. Analytical work on representations has as its principal aim the transformation of image-based representations, linked to highly intense affects, into word-presentations (Golse and Roussillon, 2010), thereby enabling the associated excitations (affects, emotions) to be bound. These image-based representations are revealed involuntarily by the analysand through his or her free associations or dream-content (Freud, 1900; Bollas, 2006). With the help of the analyst - the analyst's accompanying presence (supporting the analysand's ego) and interpretations (which clarify the unconscious and pre-conscious links behind the analysand's associations) - the analysand will be able to put into words representations that until then could not be formulated properly (Widlöcher and Fedida, 1995). This entails transforming image-based representations ("thing-presentations") into word-presentations and binding together affects and representations. In psychoanalytical theory, this is called "working-through" or "processing". In addition to working on the analysand's free associations, an important part of working-through is done via the analysis of representations, actualized in the transference relationship, of earlier relationship patterns (Levine, 2010); these can be analyzed thanks to the neutrality of the analyst who, in addition, agrees to be the target of these (transference-based) re-actualizations.

For a psychoanalyst, failures in the processing of representations play an important part in the emergence of various kinds of symptoms, hence Freud's famous comment (in the "Preliminary Communication;" Breuer and Freud, 1893): "Hysterics suffer mainly from reminiscences" (1893, p. 7). An important part of the analyst's work lies in trying to help the patient rediscover the links between representations and affects (Golse and Roussillon, 2010).

From the point of view of CBT, one of the main origins of psychological suffering lies in the avoidance of emotional experiences (Barlow et al., 2004). Since the person involved is afraid that a given emotional experience may prove too threatening and aversive, he or she will attempt to suppress or avoid it. However, since every emotion is an internal experience, it cannot be avoided. Attempts to suppress or avoid it encourage the activation of automatic (schematic) processes which maintain and exacerbate the person's emotional state. For the past 15 or so years (Hayes, 1994), CBT has come to understand the importance of subtle avoidance techniques with respect to emotions - they may turn out to be a crucial factor in psychopathology. This kind of avoidance does not consist in avoiding or suppressing all information concerning the emotional problem that is being encountered; it aims at avoiding specifically anything that could possibly evoke an emotional response. The person concerned will think about the problem to the point of brooding over it - but in an over-generalizing and abstract manner rather than in a specific and concrete way, making use of verbal rather than image-based processes from the point of view of a spectator rather than as an agent, focusing on the past and the future rather than on the present moment.

From that point of view, the work of psychotherapy consists in becoming conscious of the emotional experience and exploring it in an experiential way in the given problem situation (Philippot, 2007b). The person is encouraged not only to face up to situations that he or she fears and therefore avoids but also - and above all - to feel and explore the emotions that these situations evoke. During these emotional exposures, the individual is encouraged to adopt an experiential approach (based on what he or she actually feels) rather than an analytical one (based on the analysis of the reasons for and consequences of his or her state). This approach is facilitated by its focus on the present experience, in which the agency element is predominant, concentrating on the concrete and specific features of that experience in order to encourage the free activation of schematic/associative and propositional/conceptual systems. By encouraging the person to focus on his or her direct experience of a given situation, CBT differs significantly from the psychoanalytical approach, with its emphasis on verbalization and interpretation.

\section{THE STABILITY OF REPRESENTATIONS AND THEIR LINKS WITH AFFECTS: A SHARED ASSOCIATIVE POINT OF VIEW}

The starting point of Freud's hypothesis is that links between representations and/or between affects, given their accompanying intensity of excitation, are woven together into a network of neural connections. It assumes that "indelible" traces emerge, linked to psychical events - and in particular traumatic ones - as a result of "facilitation" (Freud, 1950 [1887-1902]). That so-created "pathway" will be taken even though the particular connection between affect and representation may change during one's lifespan. The original connection usually remains "forever" unknown. Edelman (1992) has suggested that souvenirs do not correspond to concrete fixed traces but to the souvenir of neuronal pathways linked to the experience of a given event.

In learning theory (e.g., Rescorla, 1988), the link between representation and affect is set up via contiguity and the repeated association between a given event and a feeling. Currently, learning theory also maintains that once such a link is set up, it is not easy to undo it (Bouton, 2004).

There is therefore some degree of convergence between these two approaches as regards the link between representations and affects. 


\section{THE PART PLAYED BY REPRESENTATIONS IN PSYCHOPATHOLOGICAL STATES: HOW PSYCHOANALYSIS AND COGNITIVE-BEHAVIORAL THERAPY ENVISAGE THIS}

In the early stages of cognitive theory, particularly in Lang's (1979) bio-informational theory, mental distress was thought of as being related to some pathological emotional representation or other. That representation included the elements that triggered the emotion (stimuli) and the emotional responses to these. Therefore the representation contained in itself that emotional response, in a kind of "embodied" cognition (Barsalou, 1999). This would later become more complex, with the inclusion within the representation of the meaning that is attributed to the relevant emotion. The pathological nature of the association comes from the inflexibility of the structure of relationships between the elements of the representation (a stimulus automatically leads to a particular response or activates a given meaning) and from its unrealistic and dysfunctional aspect.

As in the psychoanalytical approach, Tallis's (1999) cognitive theory describes the remembering of traumatic events in terms of unintentional thoughts or images that have proved impossible to process, given the extent of the gap between these representations in memory and the individual's own representations and models concerning how the world "ought to be" and relating to his- or herself-perception and place in the world. These "intrusions" are adaptive only insofar as they mobilize strategies that facilitate problem-solving.

Traumatic events cannot be assimilated if they are too far removed from pre-existing structures of representation. Since the structures that process emotional information are the organizers of the self, there will be repeated attempts at processing traumatic emotional information with the aim of assimilating these elements. Once they are assimilated, the information will be less easy to reactivate, because it no longer represents a challenge to the self.

That description is similar to the picture that Freud himself painted in his portrayal of traumatic neuroses, highlighting the unsuccessful and repeated attempts at binding when the too-fragile ego has been overwhelmed by a traumatic event. Freud (1926 [1925]) emphasized the fact that psychical trauma have a damaging effect. In Inhibitions, Symptoms and Anxiety, he showed how the ego can also be overwhelmed by drive-related impulses that have the effect of a psychical trauma. When faced with these internal or external dangers, the ego tries to fight against them by means of its defense mechanisms or by attempting to find a "compromise" between desire and prohibition. Both of these mechanisms may give rise to symptom-formations.

Graf and Mandler (1984), in their "associative" cognitive conception, make a distinction between integration and processing of mental representations that have an emotional content. They argue that integration is an automatic process which reinforces the internal structure of the representation. A well-integrated representation, the internal cohesion of which is solid, will easily be activated by an encounter, in the environment, with stimuli that contain some of its aspects. This is in fact a reference to what we described earlier in terms of the automatic activation of the schematic/associative system. Processing or working-through is more complex and nonautomatic; it enables the creation of associations between several representations in the cognitive network. That associative network is activated during tasks in which the individual has to search his or her memory actively for certain elements; environmental stimuli do not activate it to the same extent.

The cognitive approach describes several kinds of processing emotional information when working-through proves impossible (when the information cannot be assimilated within the associative network). Two of the main mechanisms are "suppression" and "avoidance." The terms employed here are therefore different from those used in psychoanalysis: "repression" and "splitting," for example. Just as in psychoanalytical theory-failures in working-through give rise to the "return of the repressed" expressed as symptoms - in the cognitive approach, failure to process primary emotions is pathogenic. According to Barlow and Allen (2007), avoidance is the main force behind any aggravation of emotional distress. They argue that primary emotions (those directly evoked by a given situation) are not the root cause of patients' psychological suffering; this is due to the refusal to take the primary emotion on board, thereby generating a series of secondary emotions that are pathogenic. In addition, both avoidance and suppression of primary emotions come at a price - cognitive, affect-based, and behavioral. They bring about disorders of attention, of memory or of executive functions, often create an overall sense of dysphoria, and, in behavioral terms, tend to limit the individual's sphere of activity. Hence the importance of the work of processing primary emotions.

In this approach, there are two highly subtle mechanisms for avoiding emotions: the development of abstract generalized thinking, with little in the way of images concerning the event that is being avoided, and mental ruminating. Both of these give the illusion of an attempt at processing the relevant thoughts. In therapy, the cognitive-behavioral approach attempts to process primary emotional information and more particularly, in order to limit recourse to over-generalization, to make specific the emotional perceptions and representations involved.

\section{SOME POINTS OF CONVERGENCE BETWEEN THE TWO APPROACHES: SHARING CERTAIN ASPECTS OF THEIR THEORETICAL AND THERAPEUTIC CORPUS}

In both approaches, representations play a major role in defining an experience and preforming perceptions. In both also, the failure to process adequately a memory that cannot be represented is pathogenic. In a more or less explicit manner, they maintain that the relationship between representations or between representations and affects is set up through a process of associations. In addition, they are in agreement when it comes to the part played by conscious and unconscious processes.

They agree also that difficulties which arise in the processing of some representations have to do with the fact that these cannot be assimilated or embodied within the set of representations that the individual has of the self or of the world. For both approaches, an affect/emotion is a kind of signal announcing that an event is about to pose a threat to the system of representations. The mechanisms that prevent information processing go under different names: in psychoanalysis, "repression," and in cognitive-behavioral theory, "avoidance." They agree also that failure to process information entails major repercussions of a psychopathological nature. For the psychoanalytical approach, the repressed conflict will "return," perhaps manifesting itself as symptoms. For CBT, the avoided 
emotional material or the mental effort deployed to maintain the avoidance of primary emotions will have similar consequences. As regards therapy, both approaches argue in favor of attempting to process the original information while acknowledging that that processing in itself may not be enough to free the individual from the traces left by the emotions, the learning situation or even the system of representations.

\section{WHERE THE TWO APPROACHES DIVERGE}

They differ firstly in their interpretation of the relationship between conscious and unconscious processes. For psychoanalysis, there is a separation between conscious and unconscious representations. Therefore an active process of repression lies at the heart of failures in working-through. On the other hand, cognitive approaches do not imply such an active process. They rather take into account the fact that pathogenic emotions are often automatic and implicit by nature and are difficult to regulate. Instead of "repression" as used in psychoanalysis, in cognitive-behavioral theory the preferred term relates to phenomena of activation or inhibition of representations from a multi-level perspective (several cognitive levels which correspond to different neural structures); emotional representations can be activated simultaneously at various cognitive levels, some of which are conscious, while others are automatic and not directly accessible to consciousness.

Another difference between the two approaches has to do with the nature of the relationship between affect and representation. For the cognitive approach, affects and representations, whether conscious or unconscious, are linked together. For psychoanalysis, on the other hand, affects can move from one representation to another. That idea, specific to psychoanalytical theory, entails some important clinical consequences. Displacement of an affect implies that the meaning attributed to it by the analysand (i.e., the representation with which he or she links the affect) often does not correspond to its real origin (the primary representation). The analyst listens to what the analysand is saying with the idea that there is some hidden meaning behind it; the analysand is "mistaken" as regards the meaning that he or she attributes to these affects. The work of analysis has as its principal aims making unconscious representations conscious and undoing the false associations/connections attached to them; this will, in fine, result in modifying those emotions and affects. In principle, "processing" these representations (i.e., understanding them, acknowledging the existence of "false" connections and the corresponding affects/emotions) will enable the patient to break free of them and develop new ones; in this way, the patient's mental functioning will thereafter be more flexible and varied. It should also be pointed out that the psychoanalytical approach sets great store by verbalization. Putting words on these images facilitates conscious representation which, in turn, binds excitation. The analytical process thus leads analyst and analysand to construct a biographical "history," the aim of which is to bind representations and enable changes to be made in the representational system itself.

In the cognitive-behavioral approach, the aim of the treatment was initially to modify representations by introducing new information incompatible with any pathological representation (Lang, 1979). At present, the work now being carried out in this field (Linehan, 2000; Hayes, 2002; Barlow et al., 2004) focuses more on exploring emotions, thus doing the opposite of avoidance and suppression and integrating emotional information into the individual's self-knowledge. Another important element of this approach consists in dealing with schematic aspects and in becoming aware of the bodily reactions associated with these. In exposure therapy, for example, CBT practitioners agree that it is important that there be a real exposure to the emotions that arise in emotional situations while looking out for the sometimes very subtle mechanisms by which emotions are avoided. In particular, it is essential that the person in treatment does not simply evoke the situation in which a given emotion arises without actually activating that emotion itself.

In CBT, the tendency to over-generalize emotions is looked upon as a strategy for avoiding them. When people talk in very general or abstract terms, they are attempting to avoid painful emotions. Emotional information that is too general or too abstract is difficult to modify or to “invalidate." Taking the person's own background history into account - as is done in psychoanalysis - is one way of reviving situations that have already been experienced and the representations that are linked to them. That procedure gives rise to a more specific autobiographical memory which enables a much more focused kind of work to be done on past and present emotions/affects; memory is less generalized, thus also allowing a better differentiation between past and present.

Another important difference between the two approaches lies in how they consider the thematic aspects of representations. In psychoanalysis, unconscious representations are structured in accordance with universal patterns, in particular the Oedipus complex. Only the resolution of these patterns is specific to each individual. Therefore, the themes found in unconscious representations are identical for everybody, whatever the particular experiences that each individual has. On the other hand, in the cognitive-behavioral approach, the themes encountered in representations are entirely idiosyncratic. They depend on each person's own experiences, as well as on his or her innate features and temperament. Obviously enough, in any given society, human beings will often share similar experiences, hence the fact that there may well be resemblances in some thematic aspects of their representations. These, however, are not universal; they always depend on the very concrete and personal experiences that each individual has gone through.

There is also a difference between the two approaches as to the way in which they envisage the activation of representations during the therapeutic process. In CBT, the clinical hypothesis is that the activation (optimal, not maximal) of information relating to an (underlying) schema leads to a re-experiencing of the emotions involved. The therapist has a collaborative relationship with the person being treated and suggests certain exploratory experiences that the latter can adjust to his or her capacities and motivation. In psychoanalysis, optimal activation is decided upon by the patient him- or herself. Enough space is given so that patients can take up different themes at their own rhythm (speaking freely, following particular lines of thought, free associations, the unfolding of the transference); this enables the patient to regulate how and when representations evocative of painful emotions are explored (this is one reason why psychoanalytical treatment takes so long). 


\section{CONCLUSION}

There are significant differences between the psychoanalytical and the cognitive-behavioral approach. In particular, there is a wide gap between the conditions under which theories are constructed in these two approaches. Psychoanalytical metapsychology is based on observations made by clinical practitioners. The cognitive-behavioral approach is based on empirical experimentation, which plays no part in psychoanalysis. As we conclude this paper, we must say that we think it is important to underline the fact that each approach must preserve its own specific features and acknowledge the fundamental methodological differences that do

\section{REFERENCES}

Barlow, D. H., and Allen, L. B. (2007). "The scientific basis of psychological treatments for anxiety disorders: past, present andfuture," in FearsandAnxiety: Benefits of Translational Research, ed. J. M. Gorman (Washington, DC: American Psychiatric Press), 171-191.

Barlow, D. H., Allen, L. B., and Choate, M. L. (2004). Towards a unified treatment for emotional disorders. Behav. Ther. 35, 205-230.

Barnard, P. J., and Teasdale, J. D. (1991). Interacting cognitive subsystems: a systemic approach to cognitiveaffective interaction and change. Cogn. Emot. 5, 1-39.

Barsalou, L. W. (1999). Perceptual symbol systems. Behav. Brain Sci. 22, 577-609.

Beck, A. T., Rush, A. J., Shaw, B. F., and Emery, G.D. (1979). Cognitive Therapy of Depression: A Treatment Manual. New York: Guilford.

Bollas, C. (2006). Travail de l'inconscient, transformation de l'inconscient. Fédération Européenne de Psychanalyse Bulletin 60, 139-168.

Bouton, M.E. (2004). Context and behavioral processes in extinction. Learn. Mem. 11, 485-494.

Breuer, J., and Freud, S. (1893). On the psychical mechanism of hysterical phenomena. Preliminary communication. Stand. Edn. 2, 3.

Dalgleish, T. (2004). Cognitive approaches to posttraumatic stress disorder: the evolution of multirepresentational theorizing. Psychol. Bull. 130, 228-260.

Edelman, G. M. (1992). Biologie de la conscience. Paris: Editions Odile Jacob.

Ellis, A. (1977). "The basic clinical theory of rational-emotive therapy," in Handbook of RationalEmotive Therapy, edsA. Ellis and R. Grieger (New York: Springer), 3-34.

Freud, S. (1900). L'interprétation du rêve. Stand. Edn. 2.
Freud, S. (1918 [1914]). From the history of an infantile neurosis. Stand. Edn. 17, 3 .

Freud, S. (1926 [1925]). Inhibitions, symptoms and anxiety. Stand. Edn. 20,77 .

Freud, S. (1937). Constructions in analysis. Stand. Edn. 23, 257-269.

Freud, S. (1950 [1887-1902]). Project for a scientific psychology. Stand. Edn. 1, 283.

Golse, B., and Roussillon, R. (2010). La naissance de l'objet. Paris: Presses Universitaires de France.

Graf,P., and Mandler, G. (1984). Activation makes words more accessible but not necessarily more retrievable. J. Verb. Learn. Verb. Behav. 23, 553-568.

Harvey, A., Watkins, E., Mansell, W., and Shafran, R. (2004). Cognitive Behavioural Processes Across Psychological Disorders: A Transdiagnostic Approach to Research and Treatment. Oxford: Oxford University Press.

Hayes, S. C. (1994). “Content, context, and the types of psychological acceptance," in Acceptance and Change: Content and Context in Psychotherapy, eds S. C. Hayes, N. S. Jacobson, V. M. Follette, and M. J. Dougher (Reno, NV: Context Press), 13-32.

Hayes, S. C. (2002). Acceptance, mindfulness, and science. Clin. Psychol. Sci. Pract. 9, 55-68.

Holmes, E. A., and Mathews, A. (2005). Mental imagery and emotion: a special relationship? Emotion 5, 489-497.

Lang, P. J. (1979). A bio-informational theory of emotional imagery. Psychophysiology 16, 495-512.

Laplanche, J. (2002). "Après-coup," in Dictionnaire International de la Psychanalyse, ed. A. de Mijolla (Paris: Calmann-Lévy), 121-123. [International Dictionary of

exist and constraint the implications and applications of the body of knowledge generated by each approach. Nevertheless, we believe that a rich mutual cross-fertilizing could be achieved by learning to coexist and communicate with each other. More specifically, we think that it is both possible and desirable to compare the conclusions reached by each of these approaches, not only as regards their conception of mental functioning and of the dysfunctions that generate symptoms, but also with respect to the therapeutic proposals that follow on from these. That kind of systematic comparison would enable their divergences and convergences to be explored.

Psychoanalysis. London: Macmillan, 2004; Detroit: Thomson Gale, 2005.].

Levine, H. B. (2010). Creating analysts, creating analytic patients. Int. J. Psycho-Anal. 91, 1385-1404.

Linehan, M. (2000). Traitement cognitivo-comportemental du trouble de personnalité état-limite [The CognitiveBehavioural Treatment of Borderline Personality Disorder]. Genève: Editions Médecine et Hygiène.

Philippot, P. (2007a). "La thérapie basée sur la pleine conscience: mindfulness, cognition and emotion" ["Therapy based on mindfulness: mindfulness, cognition and emotion"], in Nouvelles perspectives en thérapie cognitive [New Perspectives in Cognitive Therapy], ed. J. Cottraux (Paris: Masson), 376-393.

Philippot, P. (2007b). Emotion et psychothérapie [Emotion and Psychotherapy]. Wavre, Belgique: Mardaga. S.

Philippot, P., Neumann, A., and Vrielunck, N. (2007). "Emotion information processing and affect regulation: Specificity matters!,” in Regulating Emotions: Social Necessity and Biological Inheritance, eds M. Vandekerkhove et al. (London/New York: Blackwell Publisher), 189-209.

Rescorla, R. A. (1988). Pavlovian conditioning: it's not what you think it is. Am. Psychol. 43, 151-160.

Roussillon, R. (1999). Agonie, Clivage et symbolisation. Paris: Presses Universitaires de France.

Roussillon, R. (2008). Le jeu et l'entreje(u). Paris: Presses Universitaires de France.

Smith, C. A., and Kirby, L. D. (2000) "Consequences require antecedents: toward a process model of emotion elicitation," in Feeling and Thinking: The Role of Affect in Social Cognition, ed. J. P. Forgas (New York: Cambridge University Press), 83-106.

Tallis, F. (1999). "Unintended thoughts and images," in Handbook of Emotion and Cognition, eds T. Dalgleish and M. J. Power (Chichester: Wiley), 306-326.

Watkins, E. R. (2008). Constructive and unconstructive repetitive thought. Psychol. Bull. 134, 163-206.

Widlöcher, D., and Fedida, P. (1995). Actualité des modèles freudiens: Langage, image, pensée. Paris: Presses Universitaires de France.

Wolpe, J. (1961). The systematic desensitization treatment of neuroses. J. Nerv. Ment. Dis. 132, 189-203.

Conflict of Interest Statement: The author declares that the research was conducted in the absence of any commercial or financial relationships that could be construed as a potential conflict of interest.

Received: 16 November 2010; accepted: 05 April 2011; published online: 21 April 2011. Citation: De Timary P, Heenen-WolffS and Philippot P (2011) The question of "representation" in the psychoanalytical and cognitive-behavioral approaches. Some theoretical aspects and therapy considerations. Front. Psychology 2:71. doi: 10.3389/ fpsyg.2011.00071

This article was submitted to Frontiers in Psychopathology, a specialty of Frontiers in Psychology.

Copyright (C) 2011 De Timary, HeenenWolff and Philippot. This is an openaccess article subject to a non-exclusive license between the authors and Frontiers Media SA, which permits use, distribution and reproduction in other forums, provided the original authors and source are credited and other Frontiers conditions are complied with. 